\title{
REFLEXÕES SOBRE A DOCÊNCIA: DILEMAS E POSSIBILIDADES NAS PRÁTICAS COTIDIANAS
}

REFLECTIONS ON TEACHING: DILEMMS AND POSSIBILITIES IN DAILY PRACTICES

\author{
Josiane Sales Martins do Prado \\ Universidade Federal do Estado do Rio de Janeiro, Rio de Janeiro, RJ, Brasil. E-mail: josianeprof29@ \\ yahoo.com.br
}

Luiz Felipe Santoro Dantas

Instituto Federal de Educação, Ciência e Tecnologia do Rio de Janeiro, Rio de Janeiro, RJ, Brasil. E-mail: santoro.luizfelipe@gmail.com

Thiago Rodrigues de Sá Alves

Instituto Federal de Educação, Ciência e Tecnologia do Rio de Janeiro, Rio de Janeiro, RJ, Brasil.

E-mail: thiago.pigead@gmail.com

\section{Valéria da Silva Lima}

Instituto Federal de Educação, Ciência e Tecnologia do Rio de Janeiro, Rio de Janeiro, RJ, Brasil. E-mail: valeriaslima8910@yahoo.com.br

DOI: https://doi.org/10.46550/amormundi.v2i1.53

Recebido em: 03.01.2021

Aceito em: 28.01.2021

\begin{abstract}
Resumo: Este trabalho visa pesquisar sobre a formação dos professores e a atual realidade da sua prática em sala de aula. Para esta pesquisa utilizou-se a combinação dos métodos quantitativo e qualitativo com caráter exploratório, apoiado na pesquisa do tipo bibliográfica. Investigou-se, na perspectiva de dezoito professores que atuam no município de Barra do Piraí (RJ), quais os pontos de vista sobre a formação para a ação docente, os dilemas, fracassos e possibilidades sobre a atual situação de sucateamento e desvalorização docente, assim como suas vivências e sugestóes sobre a prática escolar. Para isso, aplicouse um questionário on-line com perguntas abertas e fechadas, por meio da plataforma Google Forms, em que a maioria dos professores alegou a necessidade de melhoria nas condições de trabalho docente, investimento na formaçáo de qualidade e garantia de políticas públicas que possibilitem a continuidade da qualificação profissional digna, eficaz e transformadora. Reflexôes, mudanças de mentalidade, prática docente emancipatória e políticas públicas de valorização docente são pontos cruciais para iniciar uma transformação libertadora de intervençâo social.
\end{abstract}

Palavras-chave: Docência. Formação. Transformação.

Abstract: This work aims to research on the training of teachers and the current reality of their practice in the classroom. For this research, the combination of quantitative and qualitative methods with an exploratory 
character was used, supported by bibliographic research. It was investigated, from the perspective of eighteen teachers working in the municipality of Barra do Pirai (RJ), what are the points of view on training for teaching action, the dilemmas, failures and possibilities about the current situation of teacher scrapping and devaluation, as well as their experiences and suggestions about school practice. For this, an online questionnaire was applied with open and closed questions, through the Google Forms platform, in which the majority of teachers claimed the need for improvement in the teaching work conditions, investment in quality training and guarantee of policies that enable the continuation of a dignified, effective and transformative professional qualification. Reflections, changes in mentality, emancipatory teaching practice and public policies for teacher appreciation are crucial points to initiate a liberating transformation of social intervention.

Keywords: Teaching. Training. Transformation.

\section{Introduçáo}

Tivemos em uma sociedade cujos interesses são bem conflituosos e controversos, principalmente quando se trata da educação e especificamente no que se refere ao professor desde sua formação profissional até sua atuação em sala de aula. Ao professor, são dadas muitas atribuiçôes e responsabilidades que muitas das vezes cabe à família e à sociedade de modo geral.

Ao pensar sobre o desempenho docente como forma de desenvolvimento profissional e da valorização do professor e melhoria da qualidade, concordamos com Jorge (2012) ao dizer que:

Importa salientar que a formação ao longo da vida se tornou um fator determinante e indubitável para qualquer profissional, de forma especial, para o professor; porque a escola de hoje necessita e exige professores capazes, autônomos, críticos, responsáveis e exigentes consigo mesmos; profissionais com desejo de fazer a diferença. Sabe-se que os professores hoje sentem-se sobrecarregados com o acúmulo de tarefas que antes eram atribuição das famílias e que agora a escola não pode esquivar-se em administrar, sob pena de ser acusada de negligente. (JORGE, 2012, p. 30).

Abrimos um parêntese para relatar a experiência de oito anos no magistério da primeira autora com experiência nos anos iniciais do Ensino Fundamental, e atualmente na Educaçáo Infantil, primeira etapa da Educaçáo Básica. Ela tem percebido, nesses anos de reflexôes e observaçóes, a desqualificação não só dos professores, mas da maior parte da sociedade que direta ou indiretamente está envolvida com o processo educativo, para que a educação de fato aconteça. Somos uma classe solitária em nosso dia a dia, temos poucos recursos materiais, pouco apoio de profissionais, com poucos direitos constitucionais e com uma formação insuficiente para superar tantos desafios.

Somente quando os oprimidos descobrem, nitidamente, o opressor, e se engajam na luta organizada por sua libertação, começam a crer em si mesmos, superando, assim, sua "conivência" com o regime opressor. Se esta descoberta não pode ser feita em nível puramente intelectual, mas da ação, o que nos parece fundamental, é que esta não se cinja a mero ativismo, mas esteja associada a sério empenho de reflexão, para que seja práxis (FREIRE, 1970, p. 29).

Reforçando a ideia de Paulo Freire, nós, professores, estamos sendo constantemente oprimidos devido às diversas atribuiçóes, pouca valorização profissional e insuficientes condiçóes para se desenvolver um trabalho em sala de aula realmente significativo. Diante do atual momento 
em que vivemos não podemos mais continuar com a mentalidade que o professor sozinho é responsável pelo fracasso da educação brasileira, uma vez que vivemos na pele a experiência de que cada um tem a responsabilidade por um todo diante da sociedade, cada um com seu papel, atribuiçóes, responsabilidade direitos e deveres.

Este estudo não visa vitimizar a classe dos professores, mas sim trazer reflexóes sobre como é ser professor nos dias de hoje, do seu próprio ponto de vista, com a intenção de dar voz a nossa classe. Oportunizar com as verdadeiras necessidades encontradas em sala de aula, como o sistema educativo influencia no trabalho do professor, como as Leis de Diretrizes e Bases (LDB) e o Estatuto da Criança e do Adolescente (ECA) influenciam em todo esse processo juntamente com os interesses políticos da nossa sociedade.

Segundo Paulo Freire (1970, p. 39), em seu livro Pedagogia do Oprimido "Já agora ninguém educa ninguém, como tampouco ninguém se educa a si mesmo: os homens se educam em comunháo, mediatizados pelo mundo.” Essa afirmaçáo nos leva a refletir sobre essa total comunhão, que seria o equilíbrio perfeito para que a educação de fato aconteça. E o que seria essa total comunhão, senão uma sociedade mais igualitária e bem estruturada a nível financeiro e familiar, com uma organização política voltada para os interesses e necessidades da sociedade e priorizando verdadeiramente a educação, uma vez que sem essa comunhão a educação não acontece em sua plenitude. Não temos dúvidas de que a educação não acontece de forma isolada onde apenas uma pessoa tem o poder e a responsabilidade de realizá-la, mas é um processo que depende de vários fatores para que ela aconteça. Por isso precisamos distribuir a cada um de forma justa e responsável o que lhe cabe, e não "depositar" em somente uma total responsabilidade.

Dessa forma, através desta reflexão e das justificativas, o objetivo deste trabalho é investigar e analisar a formação dos professores e a atual realidade da sua prática em sala de aula, mediante suas condiçôes de trabalho e trazer iniciativas para melhorá-las. Para os objetivos específicos buscamos discutir sobre as condições físicas e materiais do seu local de trabalho, suporte pedagógico e psicológico oferecidos, assim como investigar como as leis voltadas para educação influenciam no processo educativo, a desvalorização profissional e a sobrecarga de atribuiçóes.

\section{Referencial teórico}

Segundo o artigo 67 da Lei de Diretrizes e Bases da Educação Nacional, no Título VI Dos Profissionais da Educação "Os sistemas de ensino promoverão a valorização dos profissionais da educação, assegurando-lhes, inclusive nos termos dos estatutos e dos planos de carreira do magistério público" (BRASIL, 2005, p. 27). Conforme o $\$ 2^{\circ}$ deste artigo, o profissional da educação precisa ser valorizado, desde sua formação inclusive com licenciamento periódico remunerado para esse fim" (BRASIL, 2005, p. 27).

Embora esse direito seja garantido por lei, sua prática não é muito comum, e está muito distante desse tal aperfeiçoamento profissional ser acessível a todos os profissionais da educação, uma vez que estes, em sua maioria, fazem jornada dupla de trabalho. O resultado é o comprometimento do seu trabalho em sala de aula e de sua formação, devido ao cansaço e com isso muitos não buscam uma qualificação.

$\mathrm{Na}$ Finlândia, uma das maiores referências em educação no mundo, esse aperfeiçoamento 
profissional começa desde a formação dos profissionais. Sahlberg (2017) em seu livro, Liçóes Finlandesas, relata que somente os indivíduos que se destacam pela sua competência e dedicação conseguem realizar o sonho de serem professores, e o título de mestre tornou-se a qualificação básica exigida para lecionar em escolas finlandesas. Também relata que as condiçóes de trabalho são baseadas no respeito e que foram criados programas de excelência para formação de docentes, assim como uma boa remuneração para os mesmos.

No município em que a primeira autora trabalha, os programas de formação continuada, dificilmente são oferecidos. Quando há algum evento voltado para formação, são apenas palestras, restritas aos relatos de algumas teorias, que apesar de interessantes, fogem da realidade local, ou são expostas superficialmente, ou até mesmo sem recursos para conseguir colocá-las em práticas.

No livro "País Mal Educado" de Daniel Barros (2019), são apresentados diversos aspectos interessantes. Ele faz uma comparativa com a realidade de ensino de Teresina e Sobral. Mesmo Sobral sendo uma localidade mais pobre e violenta que Teresina, se destacou e oferece uma qualidade de educação pública mais elevada. As abordagens reais desse livro mostram que é possível em nosso país, ter uma educação de qualidade quando há envolvimento de fato com a educação. Dentre outras medidas em prol de uma educação de qualidade, a diretora Izolda e sua equipe apostaram na alfabetização, com ajuda da Fundação Banco do Brasil e do Instituto Ayrton Senna, criaram a meta de alfabetizar todas as crianças até os 7 anos.

Foram selecionados os melhores professores da rede, que foram inseridos para os primeiros anos do ensino fundamental, com materiais didáticos personalizados focados nos problemas característicos de Sobral, e toda equipe escolar passou a receber gratificaçóes salariais por resultados. Esse relato mostra que é possível, no Brasil, ter uma nova realidade de educação quando se tem realmente interesse e atitudes pró ativas.

Daniel Barros (2019), relata o desprestígio da carreira do professor ao apontar os resultados de sua pesquisa juntamente com a pesquisa de Bernadete Gatti publicada em 2010 dizendo que:

a maioria dos estudantes que diz "não" para a profissão cita dois fatores-chaves na justificativa: os salários não são atraentes e o trabalho requer características que eles dizem não ter (...) "não tenho paciência para criança danada", escreveu um deles numa escola de Teresina (BARROS, 2019, p.117).

Ainda no livro, Barros relata que "Falta ao sistema ao sistema público a capacidade de oferecer desenvolvimento constante das competências de seus profissionais e possibilidades claras de promovê-los com base nos resultados em sala de aula" (BARROS, 2019, p.120), e afirma que "Os resultados da pesquisa são indícios de que o magistério precisa de muito mais do que bons salários para atrair os melhores. Ele precisa oferecer uma perspectiva de aprendizado no trabalho e promoçâo para os bem-sucedidos." (BARROS, 2019, p.121).

Percebemos um aspecto fundamental para o prestígio a essa carreira que é dar mais ouvido ao que dizem os professores que estão hoje na frente de batalha, e esse aspecto é muito importante, uma vez que estamos cada vez mais sem voz com açóes pouco efetivas em sala de aula. Todavia, em Sobral, os profissionais, apesar de serem muito cobrados, uma vez que recebem bastante apoio, também recebem um incentivo financeiro e ainda estão caminhando, mas o importante é que estão em processo, e a vontade verdadeira de mudanças existe, esse é o ponto. 
Façamos uma reflexão de que se a educação for de fato prioridade de um país, teremos grandes possibilidades de ter uma sociedade mais justa e igualitária, uma sociedade em que o filho do gari e o filho do empresário estudam lado a lado, com um ensino público de qualidade, eficiente e igualitário, como já dizia Paulo Freire. Uma sociedade que veja a educação em sua totalidade, preocupada e engajada em políticas sociais e educacionais que realmente funcionem para o desenvolvimento e crescimento do país. Copiar qualquer tipo de modelo educacional, seria um equívoco, mas realidades que funcionam, são novas perspectivas e certeza, de que é possível mudar a atual realidade, o município de Sobral é uma prova disso, pois mesmo com uma realidade tão desfavorável, realiza um trabalho que se destaca diante das demais regiôes.

Ao comparar o $\$ 4^{\circ}$ da LDB, compreendemos que a progressão funcional é baseada na titulação ou habilitaçáo, e na avaliação do desempenho; ou seja, para que o professor receba sua progressão garantida por lei ele deverá ser avaliado. Infelizmente, enquanto profissional, o professor é desvalorizado. Um exemplo pode ser visto quando recebemos uma progressão, ou quando temos que ser avaliados para tal processo, uma vez que somos habilitados por lei. Em contraponto, na Finlândia os profissionais são valorizados, conforme aponta o educador finlandês Pasi Sahlberg:

Entretanto, a condição fundamental que faz com que, ano após ano, a formação de professores atraia os jovens mais capazes é o princípio de que o trabalho do professor deve ser uma profissão independente e respeitada, e não meramente voltada para a implementação técnica de padrōes, avaliaçóes infindáveis e cargas administrativas impostos de fora." (2017, p.148).

Segundo Isabel Alarcão, "não é possível desvincular currículo e pedagogia de políticas e administração. Por isso, para mudar a escola seria necessário transformar a sua organização e o modo como ela é gerida e pensada. Uma coisa é certa. Urge mudá-la." (ALARCÃO, 2001, p. 19). Nós ainda temos muito o que refletir e analisar as políticas sociais e educacionais para que realmente a educação funcione no Brasil. É possível ter uma educação de qualidade, onde o investimento, de fato, seja feito e para isso temos bons exemplos para nos inspirar. Na Finlândia os responsáveis por tomar medidas educacionais são atuantes na educação para que não tomem decisóes equivocadas. Além disso, os professores são tratados com dignidade, respeito, com orientaçôes, suporte pedagógico e psicológico, com salário digno, condiçóes de trabalho e materiais disponíveis para uso.

[...] é impossível à escola brasileira desempenhar suas funções sociais, políticas e pedagógicas sem que nela haja mudanças estruturais. Essas mudanças deverão instalar uma cultura de democratização em todas as relaçóes existentes no interior da escola, o exercício da gestão colegiada e participativa com distribuição equilibrada do poder e de responsabilidade entre todos os envolvidos no processo educativo e em todas as esferas (municipal, estadual e federal) dos sistemas de ensino (ALARCÁO, 2001, p. 75).

Em Sobral, a experiência é bem produtiva, pois criaram táticas para uma melhoria na educação, as avaliaçóes que os alunos realizam constantemente são aliadas a aulas de reforço, garantindo que os alunos aprendam a maior parte do conteúdo que demonstram náo ter aprendido antes. A avaliação é aplicada para mediar, não para punir, utilizando de ferramentas dinâmicas, assim como na Finlândia. É um longo caminho a seguir, muitas reflexôes sobre a educação e de todos os que estão envolvidos, cada um exercendo o papel que lhe cabe com equilíbrio, sem excesso para uns e quase nada para o outro lado. 
Acreditamos que o Estatuto da Criança e do Adolescente foi um avanço legal, em especial para os menores em situação de vulnerabilidade. Assim como os deveres, o ECA aborda diversos direitos garantidos por lei, na Constituição Federal em seu artigo $5^{\circ}$ dos direitos e deveres individuais e coletivos diz que:

Todos são iguais perante a lei, sem distinção de qualquer natureza, garantindo-se aos brasileiros e aos estrangeiros residentes no País a inviolabilidade do direito à vida, à liberdade, à igualdade, à segurança e à propriedade, nos termos seguintes: I - homens e mulheres são iguais em direitos e obrigaçóes, nos termos desta Constituição (BRASIL, 2016b, p. 5).

No entanto, percebemos que essa igualdade decresce quando se elabora um novo documento de direitos para um público específico, às crianças e adolescentes foram dados muitos direitos, porém faltou o equilíbrio que seria os deveres proporcionalmente. Em seu artigo 94 o ECA no artigo 94 aponta as obrigaçóes das entidades que desenvolvem programas de internação, dentre elas, oferecer cuidados médicos, psicológicos, odontológicos e farmacêuticos e propiciar atividades culturais, esportivas e de lazer.

Todos devem ter direitos e serem respeitados, sem exceção, independentemente da idade e posição social, assim como todos devem ter deveres e assumir as consequências dos seus atos. Esse desequilíbrio reflete na sala de aula, na família e na sociedade gerando um caos cada vez maior. Muitas atribuiçôes são dadas à escola e ao professor e poucas atribuiç̧óes são dadas exclusivamente à família sem regime de colaboração com outras entidades. No artigo da LDB, o único que atribui dever exclusivamente da família é o artigo $6^{\circ}$ do Direito à Educação e do Dever de Educar diz que: "É dever dos pais ou responsáveis efetuar a matrícula das crianças na educação básica a partir dos 4 (quatro) anos de idade.” (BRASIL, 2005, p. 9).

Esse excesso de deveres aos estabelecimentos de ensino e aos professores não está garantindo a qualidade de ensino nem melhores condiçôes de trabalho ao professor, pois há uma sobrecarga muito grande de um lado que está vulnerável, muitos deveres com pouquíssimos direitos sendo tratados como um ser indigno que tem que ser avaliado para que receba seu enquadramento.

Infelizmente é uma situação complicada, estamos cada vez mais distantes de ter uma educação justa e igualitária, com tantas injustiças, desigualdades e desrespeito a todos que estão envolvidos com a educação. A Constituição Federal eu seu artigo 205 garante que: "A educação, direito de todos e dever do Estado e da família, será promovida e incentivada com a colaboração da sociedade, visando ao pleno desenvolvimento da pessoa, seu preparo para o exercício da cidadania e sua qualificação para o trabalho." (BRASIL, 2016a, p. 123).

Mesmo sendo garantido por lei que a educação será promovida e incentivada com a colaboração da sociedade, na prática a educação está somente sendo promovida e incentivada pelo professor, cada vez mais solitário em sala de aula sem apoio e sem preparo, pois está cada vez mais difícil dar conta sozinho de algo que na verdade é responsabilidade de todos os envolvidos. Muitas disparidades e equívocos existem, é preciso urgentemente repensar em todas essas práticas que estáo afetando negativamente a sociedade. Percebemos que cabe ao estado cumprir com sua função e não deixar na responsabilidade da escola e nos professores.

\section{Metodologia de pesquisa}

Para esta pesquisa utilizou-se a combinação dos métodos quantitativo e qualitativo, visto 
que o uso dessa metodologia não é discordante e pode trazer um acréscimo significativo na pesquisa, cada qual com sua especificidade. Segundo Minayo (2014, p.76),

[...] a experiência de trabalho com abordagens quantitativas e qualitativas mostra que: (1) elas não são incompatíveis e podem ser integradas num mesmo projeto de pesquisa; (2) uma investigação de cunho quantitativo pode ensejar questôes passíveis de serem respondidas só por meio de estudos qualitativos, trazendo-lhe um acréscimo compreensivo e vice-versa; (3) que o arcabouço qualitativo é o que melhor se coaduna a estudos de situaçóes particulares, grupos específicos e universos simbólicos; (4) que todo o conhecimento do social (por método quantitativo ou qualitativo) sempre será recorte, uma redução ou uma aproximação; (5) que em lugar de oporem, os estudos quantitativos e qualitativos, quando feitos em conjunto, promovem uma mais elaborada e completa construção da realidade, ensejando o desenvolvimento de teorias e de novas técnicas cooperativas.

$\mathrm{Na}$ esfera qualitativa, o trabalho possui um caráter exploratório, apoiado na pesquisa do tipo bibliográfica, uma vez que foi desenvolvido através de materiais já elaborados, como livros e artigos científicos, além de se definir como uma pesquisa enriquecedora para o entendimento do objeto de pesquisa permitindo ao investigador uma ampla cobertura de dados científicos (GIL, 2008).

No primeiro momento, para a pesquisa do tema, iniciou-se o estudo por meio de busca em revistas eletrônicas; artigos científicos, por meio do recurso Google Acadêmico e da biblioteca eletrônica SciELO; leituras e análises de dissertações e teses realizadas no portal Coordenação de Aperfeiçoamento de Pessoal de Nível Superior (CAPES). Também foram realizadas leituras em livros para o aprofundamento do tema de pesquisa.

Posteriormente, foi utilizado o questionário online com perguntas abertas e fechadas, como instrumento de pesquisa através da plataforma Google Forms. As perguntas fechadas foram utilizadas para coletar informações sobre o perfil dos participantes e as perguntas abertas representam as opiniôes, pensamentos, vivências e sugestóes dentro do assunto de pesquisa abordado. De acordo com a visão de Marconi e Lakatos (2017), as questóes abertas proporcionam a construção de um conhecimento, auxiliando assim, a reflexão, a sensibilização e aproximação real, física e intelectual com o que é pesquisado.

O questionário foi dividido em dois blocos, o primeiro "Conhecendo o professor" no qual as perguntas foram destinadas para conhecer o perfil dos professores em questão e o segundo momento "Realidade da sua prática em sala de aula" para investigar o problema de pesquisa. Após a construçáo do questionário, realizou-se um teste piloto com alguns professores para investigar pequenos erros no questionário, e assim poder melhorar para o compartilhamento.

Após sua validação, o questionário foi compartilhado com professores regentes nos anos iniciais do Ensino Fundamental e contou com participação de 18 professores que colaboraram com suas participaçóes e ajudaram a investigação do tema.

\section{Resultados e discussáo}

Após a coleta dos dados, procedeu-se à análise dos resultados. Para o primeiro momento "Conhecendo o professor" observamos que dentre os 18 professores participantes, a maioria possui faixa etária entre 36 a 45 anos, tendo a maior parte dos professores experiência na área docente em média de 6 a 10 anos. Dos 18 professores, 12 possuem Licenciatura em Pedagogia e 
uma parcela de 6 professores possuíam especialização. A maioria trabalha no município de Barra do Piraí (16 professores), atuando, em sua maioria, na Educação Infantil.

No segundo momento da pesquisa, "Realidade da sua prática em sala de aula" investigamos algumas questóes interessantes como podemos observar a seguir. Sobre a questão de que os professores desejariam se qualificar além da graduaçáo, o mestrado foi a resposta que teve maior preferência entre os professores, totalizando 11 respostas, contra 7 de especializaçáo e 2 o doutorado. Vale ressaltar que os professores poderiam escolher mais de uma opção para a resposta.

No entanto, esse desejo é impossibilitado de se tornar realidade por alguns fatores. De acordo com a pesquisa, 12 (66,7\%) professores alegam que não realizam graduaçóes em níveis mais elevados, devido ao cansaço, pois têm uma jornada cansativa para aumentar a renda. Uma triste realidade que afeta a maior parte da classe, uma vez que são mal remunerados e necessitam trabalhar mais, para aumentar sua renda mensal. Alguns outros fatores são de importância mencionar: o desânimo com a educação, não vendo sentido em se especializar, pois não há reconhecimento nem retorno financeiro e uma parcela dos entrevistados alega não ter condiçóes financeiras para cursar uma pós-graduação.

Completando esse aspecto, A Lei de Diretrizes e Bases da Educação Nacional, no Título VI - Dos Profissionais da Educação em seu artigo 67 aponta que "Os sistemas de ensino promoverão a valorização dos profissionais da educação, assegurando-lhes, inclusive nos termos dos estatutos e dos planos de carreira do magistério público" (BRASIL, 2005, p.27). Ao perguntar sobre o plano de cargos e carreira, somente 1 professor, dos 18 pesquisados, afirma ter recebido esse direito garantido por lei, mas sem aplicação na maioria dos municípios; direito esse que elevaria o salário dos professores, melhorando suas condições financeiras e aumentando a possibilidade em se graduarem em níveis mais elevados de ensino.

Confirmamos essa triste realidade, ao perguntar se "Você se sente valorizado financeiramente assim como segura a LDB?”. Dos 18 professores, 16 não se sentem valorizados, assim como assegura a Lei de Diretrizes e Bases da Educação Nacional. Cabe a todos nós refletir sobre essa ausência de cumprimento das leis que garantem um pouco mais de dignidade e valorização dos profissionais da educação. Investigou-se também que tipo de ajuda de custo ou benefício oferecido pelo município os professores recebiam. Metade dos professores recebem auxílio transporte, por outro lado a outra metade não recebe nenhum tipo de ajuda de custo ou benefício. Dos 18 professores, 2 recebem remuneração por regência, 2 recebem porcentagem do Fundo de Manutenção e Desenvolvimento da Educação Básica e de Valorização dos Profissionais da Educação (FUNDEB), e apenas 1 recebe auxílio alimentação. Esse resultado demonstra a triste realidade do professor, que trabalha cada vez mais e recebendo cada vez menos, com pouquíssimos benefícios.

Ao investigar se os professores exerciam outro tipo de trabalho para aumentar sua renda, 5 professores realizam outros trabalhos, além de lecionar. Apesar de ser minoria, devemos considerar os professores que trabalham em outros municípios e fazem dobras nos mesmos. Diante disso, essa porcentagem chega a ser preocupante, uma vez que para aumentar sua renda, realizam atividades externas, como podemos verificar nas respostas de alguns professores:

- Vendas de produtos; 
- Venda de tênis;

- Pego aulas extras na rede;

- Costura e bordado;

- Tenho uma mini lanchonete, onde vendo lanches (todos os dias) e almoço (finais de semana).

Vivemos em uma sociedade onde políticas públicas não são aplicadas de forma justa e igualitária. Investigamos se os professores em questôes recebiam algum suporte psicológico, cuidados médicos, odontológicos e/ou farmacêuticos oferecidos gratuitamente pelo município em que trabalham. A resposta foi bem preocupante, uma vez que os profissionais da educaçáo, que estão cada vez mais expostos a vários tipos de violência, não recebem nenhum suporte. Uma sociedade que se preocupa e investe cada vez menos na educação, esse questionário vem comprovar isso, essa triste realidade, que deve ser repensada e analisada com bastante seriedade e bom senso, para que a educação se torne realmente justa, igualitária e humana e eficaz.

Ao investigar se o professor sofreu algum tipo de violência dentro do ambiente escolar, 6 professores informaram que já sofreram violência verbal, 6 professores foram oprimidos pela equipe diretiva da escola e 3 já sofreram violência física. Nessa mesma perspectiva, analisando as respostas, a maioria dos professores já sofreu algum tipo de problema de saúde causado pelo trabalho, como a depressão, crise de ansiedade, pânico e pressão alta.

Mesmo sendo garantido por lei as boas condiçôes de trabalho em sala de aula, 77,8\% (14 professores) afirmam não ter boas condições de trabalho. A educação é um processo que se dá pela junção de vários fatores e aspectos, quando tantos aspectos ocorrem de forma tão negativa e injusta, sem o cumprimento de direitos garantidos por lei, direitos básicos e não abusivos, considerando que a educação depende de um todo, é importante refletirmos sobre o resultado abaixo e pensar em como mudar uma realidade táo desfavorável para uma educação de qualidade.

Sobre a organização e planejamento, 12 professores (66,7\%) afirmaram que a escola não disponibiliza um tempo periódico para planejamento e organizaçáo das aulas, ou seja, a maior parte dos professores além de não receberem direitos garantidos por lei que deveriam aumentar sua renda mensal, que já sofrem com problemas de saúde, são violentados de várias formas, sem nenhum tipo de suporte médico oferecido pelo município que trabalha, ainda levam trabalho para casa.

A educação é um processo que depende de um todo, ela não acontece de forma isolada, e o professor não foge desse princípio, um professor que não recebe plano de cargo e carreira garantido por lei, sem boas condiçôes de trabalho em sala de aula, sem benefícios, violentados, desvalorizados e sobrecarregados vão conseguir pensar em se qualificar em níveis mais elevados de ensino, uma vez que não terão tempo nem dinheiro para se qualificarem.

Ao responderem de forma discursiva sobre suas reais condições de trabalho, em relação a materiais, estrutura física da escola, formação das turmas, entre outros aspectos que quiseram abordar, dentro de aspetos de impedem que o professor tenha boas condiçóes de trabalho, separamos alguns relatos importantes.

- Como o salário é consideravelmente pouco temos que trabalhar os dois turnos e com isso o cansaço dobra também. Sáo turmas numerosas, com falta de acompanhamento familiar, 
consideram a escola como um depósito, não se preocupando com o real papel da escola e de todos os educadores ali envolvidos e outra questão preocupante é a educaçáo inclusiva que muitas vezes não acontece por falta de preparo dos profissionais que muitas vezes por falta de tempo, cansaço e descaso por parte dos órgãos competentes não conseguem aprimorar suas práticas e sáo cobrados para realizar um trabalho muitas vezes incompreendido por eles;

- Poucos recursos materiais, espaço muito pequeno e muitas crianças, sem auxiliar em sala de aula. Pouca formação continuada e as que temos, são abordados assuntos não muito relevantes. Fora a remuneração que não condiz com o trabalho desgastante, sendo assim cada vez mais desvalorizado.

- Sala de aula incompativel com o número de alunos, falta de material, falta de formação e como trabalho com educação infantil a falta de auxiliares na rotina diária. Salário estagnado desde que entrei no municipio e a falta de direitos básicos.

- Trabalho em lugar de difícil acesso onde por muitas vezes compramos material, custeamos comemoraçóes, passamos da carga horária. As condiçóes físicas da escola são boas, mas ano passado trabalhei em uma escola que o banheiro não tinha descarga, refeitório em péssimas condiçôes e o teto caiu em pleno ano letivo.

- Falta material escolar, a estrutura física necessita passar por constantes reformas e suporte profissional para lidar com problemas de alunos que excede o campo pedagógico.

- Quanto a infraestrutura ainda deixa a desejar, quadro negro antigo que ainda utiliza giz branco, meia parede que atrapalha muito, pois o barulho é grande, salas quentes com ventiladores quebrados, iluminação também ruim. Isso tudo acaba atrapalhando não só nós professores com também os alunos principalmente. Pois um ambiente acolhedor ajuda muito no processo de aprendizagem.

Para que o professor possa desempenhar seu trabalho com qualidade, o municipio precisa oferecer materiais durante todo ano letivo, melhorias na infraestrutura física como por exemplo o fechamento das paredes dos CIEPs, nas quais se apresentam o barulho externo exige grande esforço por parte do professor; turmas com muitos alunos, principalmente nos anos iniciais do ensino fundamental onde as crianças ainda são muito dependentes do professor; e a falta de valorização salarial que representa um dos fatores de grande rotatividade de professorado no munícipio.

- Capacitação para aprimorar o trabalho principalmente com os alunos de inclusão. Falta apoio da equipe diretiva. A falta de responsáveis mais atuantes na vida escolar dos alunos. Salário baixo...

- A rede municipal oferece o mínimo de condiçóes, nós professores que muitas das vezes tiramos do bolso para ofertar uma melhor qualidade para a aprendizagem dos alunos. Comprei e carrego um notebook, onde gravo videos como apoio para melhorar a qualidade de ensino, pois o avanço da tecnologia não chegou à realidade escolar, temos que usar muita criatividade e amor a educação!!!!!

Nós professores encontramos em nosso dia a dia, um ambiente totalmente desfavorável para uma educação de qualidade, justa e igualitária. Sabemos que o amor é um fator essencial para desenvolver um bom trabalho, mas não devemos esquecer que outras capacidades também são essenciais. Somos profissionais da educação e precisamos ter autoridade, conhecimento, 
domínio de conteúdos e saberes, precisamos de capacitação constante, sermos valorizados e respeitados, com uma remuneração digna dentro do que está previsto na lei, assim como ter boas condiçóes de trabalho.

Somos responsáveis pela formação de outras pessoas e isso é muito sério, o conhecimento é libertador, e os profissionais da educação precisam cada vez buscar essa liberdade para se libertarem dessa triste realidade. No livro Liçôes Finlandesas (p.31), escrito por Pasi Sahlberg, país referência em educação, diz que:

A experiência finlandesa sugere que não é suficiente estabelecer programas de excelência para a formação de professores sem remunerar bem os professores. A Finlândia criou programas de excelência para formação de docentes. E paga bem os seus professores. (SAHLBERG, 2017, p.31)

Como já dito por anteriormente, a visão sobre uma educação continuada por si só não é suficiente. Para uma educação de qualidade e de referência, é preciso de diversos fatores e condiçóes para que faça diferença de fato. É necessário que esta seja de qualidade e ocorra periodicamente, de forma significativa, que seja possibilitado aos professores se capacitarem de forma digna. E para que este profissional tenha de fato capacitaçóes continuadas em níveis mais elevados precisa haver uma mudança na atual realidade escolar.

Fatores esses descritos nas respostas abaixo, relacionadas a seguinte pergunta: Que medidas você considera que deveriam ser tomadas para que essa triste realidade mudasse?

- Sala de aula com um número menor de crianças.

- Investimento na educação de qualidade com formação integral do educando em primeiro lugar por parte do governo brasileiro e não a manutenção de uma educação bancária, como diria Paulo Freire, para manutenção desse sistema corrupto. E uma conscientização da importância da educaçâo como algo primordial para a qualidade de vida de todos os cidadãos brasileiros por meios de comunicação de massa, financiados pelo governo, pois acredito ser algo mutável culturalmente, o foco seria criar na população perspectiva de vida com base na formação integral. Para tentar a longo prazo recuperar essa trajetória de pobreza, violência, desemprego, preconceitos, crises econômicas e principalmente corrupçâo.

- É necessário termos mais capacitaçóes, pois temos muitas cobranças e devemos nos desdobrar para cumprir as solicitaçôes sem termos as devidas orientaçôes; valorização do nosso trabalho; uma remuneração digna de um profissional da educação. Enfim sermos simplesmente, valorizados.

- Seguir as leis vigentes que garantem os direitos de todos envolvidos no processo.

- Punição mais severas aos municipios e seus gestores que descumprisse tais leis.

Investimento na educação e aumento do salário dos profissionais que trabalham a educação.

- O poder público deveria dar um pouco mais de atenção a Educação, visando melhorar as condiçóes de trabalho do professor e assim consequentemente melhorando o ensino.

- Investir fato na educação, com salários adequados o cumprimento do plano de cargo e carreira, divisão das turmas para que não fiquem numerosas, facilitar a formação do professor.

- Valorização da parte do governo e investimento na educação.

- Que houvesse mais fiscalização por meio do governo federal junto as Prefeituras.

- Que a prefeitura aumentasse o nosso salário e desse internet a todos. 
- Um olhar diferenciado para a educação e que houvesse uma fiscalização rígida sobre os governantes (prefeitos ou governadores).

\section{- O cumprimento da lei, principalmente no que tange o plano de cargos e salários.}

Diante dessas respostas fica claro a unidade que deveria existir entre o bom funcionamento de todos os aspectos citados acima. São propostas possíveis de se realizar e que traria excelentes resultados, com grandes chances de uma melhora significativa na educaçáo e consequentemente na sociedade. Segundo Barros (2019), os gargalos para uma educação de qualidade são: a formação e seleção de professores, currículo, educação integral e boa gestão. Certamente uma mudança de mentalidade, é o primeiro passo que deve ser dado, é possível dentro da realidade de cada município e ou país, fazendo as necessárias adaptaçóes de transformar uma sociedade falida em uma referência em educaçáo, com atitudes positivas, eficazes, justas e responsáveis.

É possível sim a educação transformar essa realidade tão desfavorável, pensando na educação como um todo, desde a mudança de mentalidade até suas ações transformadoras. Não é utopia, é real, isso existe e pode ser possível, desde que haja de fato um verdadeiro investimento na educação e que esta seja a prioridade de governo, assim como foi na Finlândia, que a educação seja o recurso político para mudar a situação do país.

É fundamental que estejamos em constante processo de formação, para conseguirmos transformar essa realidade cruel, que permeia a maior parte do nosso país, uma vez que o conhecimento é libertador. De acordo com essa ideia Nóvoa (1992, p. 25) considera que a formação deve estimular uma perspectiva crítico-reflexiva, que forneça aos professores os meios de um pensamento autônomo e que facilite as dinâmicas de autoformação participada. Formação é o ponto chave, uma sociedade crítica, com conhecimento aprofundado e não superficial, no qual não aceita políticas desfavoráveis, mas luta por uma transformação necessária.

Compreendemos que somos todos responsáveis pela verdadeira transformação, não somos adversários, mas um conjunto de forças que quando somadas em prol de algo maior todos sairemos vencedores. Paulo Freire enfatiza que,

ninguém começa a ser educador numa terça-feira às quatro horas da tarde. Ninguém nasce educador ou marcado para ser educador. A gente se forma educador, permanentemente, na prática e na reflexão sobre a prática. (FREIRE, 1991, p. 58).

Assim como tudo pode ser transformado, com boa vontade, conhecimento e luta. É preciso, segundo Alarcão (2001, p.19), pensar sobre os valores e as relaçóes humanas que se vivem na escola. "É preciso repensá-la, pensando-a em contexto. Mas não basta que fiquemos apenas no pensar. Depois, é preciso agir para transformá-la.”.

\section{Consideraçóes finais}

Diante do exposto, a respeito da formação dos professores, para que esta seja realmente significativa e transformadora, e não mais uma obrigação a ser cumprida, as reais condiçóes de trabalho em sala precisam ser favoráveis a todos os envolvidos no processo de ensino e aprendizagem. E que sejam justas e humanas aos profissionais da educação e aos educandos.

Professores atuantes em sala de aula disseram ser preciso que o poder público tenha mais atenção e preocupação com a Educação, para melhorar as condiçóes de trabalho deles 
e consequentemente melhorar o ensino. É preciso fazer cumprir as leis vigentes para que o professor tenha um pouco mais de dignidade e condições favoráveis para realização do seu trabalho. Sabemos que não é um caminho fácil, muitas coisas estão envolvidas, mas o importante é saber que é possível construir um caminho diferente do que já existe, mudar é preciso, reflexóes como essas abordadas neste texto precisam ser mais discutidas, para que se tornem, em um futuro próximo, em práticas reais de transformação e mudanças na educação em todos os seus aspectos, em sua totalidade.

Tornar possível uma mudança nesse nível é mudar a mentalidade de que estamos fadados a este tipo de educaçáo, vivendo em sociedade cada vez mais desigual e desfavorável para o progresso de toda a educação. É possível e real uma sociedade ou uma parte dela ser transformada pela educação, quando esta acontece verdadeiramente, vimos isso acontecer no Sobral, realidade brasileira, e na Finlândia. Investir em educação, tê-la como prioridade de governo, deve ser a meta de uma sociedade que está cada vez mais marginalizada e distante de ter uma vida digna e justa com possiblidades reais de transformação. Juntos somos um todo que faz a diferença.

Náo podemos agir de forma isolada, mas se cada um fizer a parte que lhe cabe faremos a diferença de que tanto precisamos. Que continuemos caminhando juntos, com mudança de mentalidade, reflexão sobre a prática e a busca por políticas públicas de valorização docente.

\section{Referências}

ALARCÃO, Isabel. Escola reflexiva e a nova racionalidade. Porto Alegre: Artmed, 2001.

BARROS, Daniel. País Mal Educado: Por que se aprende táo pouco nas escolas brasileiras? 2. ed. Rio de Janeiro: Record, 2019.

BRASIL. Constituição da República Federativa do Brasil 1988. Brasília: Senado Federal, 2016a. Disponível em https://www2.senado.leg.br/bdsf/bitstream/handle/id/518231/CF88_ Livro_EC91_2016.pdf Acesso em mar. 2020.

BRASIL. Constituição da República Federativa do Brasil. Texto consolidado até a Emenda Constitucional no 95 de 15 de dezembro de 2016. Brasília, Senado Federal, 2016b. Disponível em https://www.senado.leg.br/atividade/const/con1988/con1988_15.12.2016/ CON1988.pdf Acesso em mar. 2020.

BRASIL. Lei de Diretrizes e Bases da Educaçáo Nacional. Lei no. 9.394de 20 de dezembro de 1996. Brasília, Senado Federal, 2005. Disponível em https:/www2.senado.leg.br/bdsf/ bitstream/handle/id/70320/65.pdf Acesso em mar. 2020.

FREIRE, Paulo. Pedagogia do Oprimido. 17a ed. Rio de Janeiro. Paz e Terra, 1987.

GIL, Antônio Carlos. Métodos e técnicas de pesquisa social. 6 ed. São Paulo: Atlas, 2008.

JORGE, Therezinha Teodoro de Paula. A avaliação do desempenho docente como forma de desenvolvimento profissional, valorização do professor e melhoria da qualidade de ensino no estado do espírito santo - brasil - um estudo de caso. Dissertaçáo de Mestrado. Escola Superior de Educação Almeida Garrett, Lisboa, Portugal, 2012. Acesso em dez 2020 em: https://recil.grupolusofona.pt/bitstream/10437/3286/1/Dissertacao_VersaoFinal3_ Therezinha_29_11_2012.pdf 
MINAYO, Maria Cecília de Souza. O Desafio Do Conhecimento: Pesquisa Qualitativa Em Saúde. 14. ed. São Paulo: Hucitec, 2014.

NÓVOA, António Sampaio da. A formaçáo de professores e profissão docente. Lisboa: Dom Quixote, 1992.

SAHLBERG, Pasi. Liçóes Finlandesas: O que o mundo pode aprender com a mudança educacional na Finlândia? Tradução: Elena Gaidano. Niterói: Eduff, 2017. 